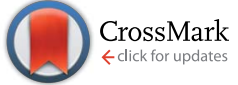

Cite this: RSC Adv., 2017, 7, 300

\title{
Effective conversion of biomass into bromomethylfurfural, furfural, and depolymerized lignin in lithium bromide molten salt hydrate of a biphasic system $\dagger$
}

\begin{abstract}
Chang Geun Yoo, Shuting Zhang and Xuejun Pan*
A novel approach using a biphasic system consisting of a molten lithium bromide hydrate solution $\left(\mathrm{LiBr} \cdot 3 \mathrm{H}_{2} \mathrm{O}\right)$ and an organic solvent was developed to efficiently produce furan-based chemicals from cellulose and lignocellulosic biomass. At $125^{\circ} \mathrm{C}$ for $2 \mathrm{~h}$, the yield of bromomethylfurfural (BMF) from cellulose reached $>90 \%$ (molar yield), and the yields of furfural (FF) and BMF from real biomass (herbage, hardwood, and softwood) were $\sim 70 \%$ and $\sim 85 \%$, respectively. The reaction mechanisms of the polysaccharides and lignin and the role of the molten salt hydrate were investigated and elucidated. In the biphasic system, hemicelluloses and cellulose of the biomass were dissolved, hydrolyzed, dehydrated and brominated to FF and BMF, respectively, in the aqueous phase, and the furan products were simultaneously extracted into and cumulated in the organic phase. Meanwhile, lignin in the biomass was significantly depolymerized through the cleavage of $\beta$-aryl ether linkages and separated with high purity for potential coproducts.
\end{abstract}

Received 10th October 2016

Accepted 24th October 2016

DOI: $10.1039 / c 6 r a 25025 d$

www.rsc.org/advances

catalysts in aqueous or organic solvents. ${ }^{17,26-29}$ However, the production of these furans remains challenging due to low yield, poor selectivity, and environmental issues of the associated processes. ${ }^{5}$ Currently, the annual FF production is more than 200000 tons worldwide, but the current yield is only about $50 \%$ of the theoretical yield due to the aforementioned side reactions. ${ }^{30}$ Recently, halomethylfurfurals such as 5-bromomethylfurfural (BMF) and 5-chloromethylfurfural (CMF) have been investigated as platform chemicals for the production of solvents, polymers, and liquid hydrocarbon fuels. ${ }^{31-35}$ Diverse approaches were explored, but these processes had some limitations such as high acid loading or concentration, unsatisfactory product yield, and insufficient utilization of hemicelluloses and lignin..$^{26,27,29,31,32}$

For effective conversion of biomass to the furans, selection of a proper reaction medium is crucial. In the previous studies, water with acid catalyst was the most common medium, but low yield and poor selectivity are the major issues due to the rehydration of HMF to levulinic acid and formic acid and/or the condensation of the furans to humins. ${ }^{17,36-38}$ It was found that ionic liquids (ILs) and high boiling point organic solvents, such as dimethylsulfoxide and $N, N$-dimethylformide, were able to improve the furan yield; however, these processes are economically unfavorable because of the high costs for solvent and downstream processing. . $^{17,27}$

In this study, we developed a simple and effective biphasic system involving molten salt hydrate to convert biomass into furans (FF and BMF) under mild conditions. Different molten

Department of Biological Systems Engineering, University of Wisconsin-Madison, 460 Henry Mall, Madison, WI 53706, USA. E-mail: xpan@wisc.edu

$\dagger$ Electronic supplementary information (ESI) available: Experimental details, optimization of reaction conditions, and NMR data for product quantification and lignin characterization. See DOI: 10.1039/c6ra25025d 
halide salt hydrates for the aqueous phase and varying solvents for the organic phase were compared. The effects of the salt concentration and solvent volume on the yields of furans were also examined. The role of the molten salt hydrate and the reaction mechanism of cellulose conversion to BMF were investigated. Separated lignin was characterized by means of wet-chemistry analysis, GPC, and NMR to elucidate the lignin reactions and evaluate the potential for lignin co-products.

\section{Experimental section}

\subsection{Materials}

$\mathrm{D}(+)$-Glucose, $\mathrm{D}$-fructose, and $\mathrm{D}(+)$-cellobiose were purchased from Fisher Scientific (Pittsburgh, PA), and microcrystalline cellulose was purchased from Sigma-Aldrich (St. Louis, MO). Lithium bromide $(\mathrm{LiBr})$ and calcium bromide $\left(\mathrm{CaBr}_{2}\right)$ were from Alfa Aesar, and lithium chloride ( $\mathrm{LiCl}$ ) was from Fisher Scientific. Hydrochloric acid (37 wt\%), hydrobromic acid (48 wt\%), and solvents including dichloromethane (DCM), toluene, benzene, and cyclohexane were purchased from Fisher Scientific. Lignocellulosic biomass including corn stover, switchgrass, poplar, aspen, and Douglas fir was air-dried at ambient temperature, ground with a Wiley mill, and the fraction between 10 and 50 mesh was used in this study.

\subsection{Experimental set-up}

All the reactions were conducted in a stainless steel reactor with Teflon liner (50 mL of internal volume), as shown in Fig. S1. $\dagger$ For uniform reaction, a magnetic bar was used to stir at $500 \mathrm{rpm}$. A glycerol bath was used for heating, controlled by a hotplate (CG-1994-50, Chemglass, NJ). In a typical experiment, 0.2-1.0 $\mathrm{g}$ (oven dry weight) of a feedstock were loaded into the reactor with $10 \mathrm{~mL}$ of aqueous solution of salt with acid cocatalyst and 10-20 mL of organic solvent. At the end of reaction, the reactor was cooled down to room temperature, and then the mixture in the reactor was transferred to a Falcon ${ }^{\mathrm{TM}}$ conical centrifuge tube (Fig. S2 $\dagger$ ). Centrifuge at $4500 \mathrm{rpm}$ for $10 \mathrm{~min}$ and carefully collect the solvent layer (organic phase, top) for the quantitation of furan products using NMR and GCMS analyses, as described below.

\subsection{Quantitation of furans with NMR and GC-MS}

Transfer $1 \mathrm{~mL}$ of the organic phase into a $2 \mathrm{~mL}$ vial. The organic solvent was carefully removed using a rotary evaporator (Rotavapor R-215, Switzerland), and the remaining products were dissolved in chloroform-d $(1 \mathrm{~mL})$ for NMR analysis. NMR spectra were acquired at $293 \mathrm{~K}$ on a Bruker Instruments Avance III 500 console, $11.74 \mathrm{~T}$ standard bore magnet NMR spectrometer, equipped with a $5 \mathrm{~mm}$ DCH cryoprobe. ${ }^{1} \mathrm{H}-\mathrm{NMR}$ ( $\mathrm{ns}=16$, $\mathrm{ds}=2, d_{1}=8 \mathrm{~s}$ ) was used to quantitate furan-based products such as BMF, CMF, and FF (Fig. S3 in ESI $\dagger$ ). Specifically, BMF was quantitated by comparing the quantity of the protons in the samples with the protons in the internal standard (pyrazine), as presented in Fig. S3(a) in ESI. $\dagger$ FF and CMF were quantitated with a similar method. The molar yields of the furan-based products were calculated based on the initial pentoses or hexoses available in the feedstock with an assumption that one mole of monosaccharide would produce one mole of furanbased product. Targeted peaks of BMF were assigned at: $\delta=$ $6.55 \mathrm{ppm}\left({ }^{1} \mathrm{H}\right) \& 112.3 \mathrm{ppm}\left({ }^{13} \mathrm{C}\right) ; \delta=7.16 \mathrm{ppm}\left({ }^{1} \mathrm{H}\right) \& 122.2 \mathrm{ppm}$ $\left({ }^{13} \mathrm{C}\right)$; targeted furfural peaks were assigned at: $\delta=6.63 \mathrm{ppm}$ $\left({ }^{1} \mathrm{H}\right) \& 112.7 \mathrm{ppm}\left({ }^{13} \mathrm{C}\right) ; \delta=7.22 \mathrm{ppm}\left({ }^{1} \mathrm{H}\right) \& 121.8 \mathrm{ppm}\left({ }^{13} \mathrm{C}\right)$ in the NMR spectra (Fig. S4 in ESI $\dagger$ ). ${ }^{1} \mathrm{H}$-NMR quantification method was verified by gas chromatography-mass spectrometry (GC-MS) (GCMS-QP 2010S, Shimadzu Co., Addison, IL) equipped with SHRXI-5MS column $(30 \mathrm{~m} \times 0.25 \mathrm{~mm}$ I.D., $0.25 \mu \mathrm{m})$, using furfural as standard (Fig. S5 in $\mathrm{ESI} \dagger$ ). The GC oven temperature was programmed as follows: $100{ }^{\circ} \mathrm{C}$ for $1 \mathrm{~min}$, ramp to $310^{\circ} \mathrm{C}$ at $5{ }^{\circ} \mathrm{C} \mathrm{min}{ }^{-1}$ and hold for $7 \mathrm{~min}$. The flow rate of carrier gas (helium) was set to $22 \mathrm{~mL} \mathrm{~min}{ }^{-1} \cdot{ }^{13} \mathrm{C}-\mathrm{NMR}$ analysis was conducted to confirm the structures of BMF and CMF (Fig. S3(b) in ESI $\dagger$ ). ${ }^{13} \mathrm{C}$-NMR spectra from BMF $(\delta=21.8 \mathrm{ppm})$ and $\operatorname{CMF}(\delta=36.1 \mathrm{ppm})$ were used to identify and quantify the formation of BMF and CMF. This result was also confirmed with GC-MS results (Fig. S5 in ESI $\dagger$ ).

\subsection{Solution-state NMR analysis of whole biomass and separated lignins}

Whole biomass (Douglas fir and poplar) and separated lignins from the biomass by the biphasic process were characterized with solution-state NMR analysis. For untreated whole biomass, the dried sample was pre-ground passing 50 mesh and then Soxhlet-extracted with water and ethanol for $24 \mathrm{~h}$. The extractives-free sample was air-dried and further ball-milled using a PULVERISETTE 7 ball mill at $600 \mathrm{rpm}$ in a $\mathrm{ZrO}_{2}$ vessel $(50 \mathrm{~mL})$ containing $\mathrm{ZrO}_{2}$ ball bearings $(10 \times 10 \mathrm{~mm})$. Each sample $(200 \mathrm{mg})$ was milled for $1-2 \mathrm{~h}$ in $10 \mathrm{~min}$ intervals with 5 min interval breaks to avoid excessive heating. For the separated lignin, no pretreatment was needed. To prepare sample for solution-state NMR, the ball-milled biomass or the separated lignin $(50 \mathrm{mg}$ ) was transferred into a $5 \mathrm{~mm}$ NMR tube, mixed with DMSO- $d_{6} /$ pyridine- $d_{5}(4: 1, \mathrm{v} / \mathrm{v}, 0.5 \mathrm{~mL})$.

Solution-state NMR spectra were acquired on a Bruker Instruments Advance III 500 console equipped with a cryoprobe. The central DMSO solvent peak was used as internal reference $\left(\delta_{\mathrm{C}} 39.5, \delta_{\mathrm{H}} 2.49 \mathrm{ppm}\right)$. HSQC experiments were carried out using following parameters: acquired from 11 to $1 \mathrm{ppm}$ in $\mathrm{F} 2\left({ }^{1} \mathrm{H}\right)$ with $100 \mathrm{~ms}$ acquisition time, 220 to $20 \mathrm{ppm}$ in $\mathrm{F} 1\left({ }^{13} \mathrm{C}\right) 8 \mathrm{~ms}$ acquisition time; the $d_{1}$ was set $1 \mathrm{~s}$ and number of scans was 32. Volume integration of contours in HSQC plots used Bruker's TopSpin software.

\subsection{GPC analysis of separated lignins}

The weight-average molecular weight $\left(M_{\mathrm{w}}\right)$ and number-average molecular weight $\left(M_{\mathrm{n}}\right)$ of the separated lignins from three species of biomass including switchgrass, poplar, and Douglas fir were estimated by gel-permeation chromatography (GPC) on a HPLC system (ICS 3000, Dionex) with a UV detector. One guard column (Phenomenex Cat\# 03B-2088-K0) and three analytical Phenogel $(5 \mu \mathrm{m})$ columns with pore size of $10000 \AA$ (Phenomenex Cat\# 00H-0445-K0), $500 \AA$ (Phenomenex Cat\# 00H-0443-K0), and $50 \AA$ (Phenomenex Cat\# 00H-0441-K0) were 
connected in series, and the column temperature was maintained using a column heater ( $\mathrm{CH}-460$, Eppendorf) with a temperature controller (TC-50, Eppendorf). The lignin was acetylated in pyridine/acetic anhydride $(1: 1, \mathrm{v} / \mathrm{v})$ to improve the solubility in tetrahydrofuran (THF). The lignin (10 mg) was suspended in $2 \mathrm{~mL}$ pyridine/acetic anhydride mixture and kept in the dark for $72 \mathrm{~h}$. The mixture was poured into cold acidic water and stirred for $1 \mathrm{~h}$. The precipitate was collected, washed with deionized water, and then dried in a freeze dryer. The acetylate lignin was dissolved in THF and filtered by a syringe filter. The THF solution $(10 \mu \mathrm{L})$ was injected onto the GPC columns with an eluent (THF) flow rate of $1.0 \mathrm{~mL} \mathrm{~min}{ }^{-1}$ at $30{ }^{\circ} \mathrm{C}$. A set of polystyrene standards and aromatic compounds were used for calibration.

\subsection{Experimental design and software}

The conversion of cellulose to BMF in the biphasic system was optimized using response surface methodology (RSM) following the quadratic central composite design (CCD). Twenty points were tested with three variables (reaction temperature, reaction time, and hydrobromic acid ( $\mathrm{HBr}$ ) loading), and each variable varied at three levels $(\alpha=1.0)$. BMF yield was the response (dependent variable). Each reaction point was conducted in duplicate. Design Expert software (version 7.1.1, Stat-Ease, Inc., Minneapolis, MN) was used for the experiment design and statistic analysis of data.

\section{Results and discussion}

\subsection{Description of the proposed biphasic system}

The biphasic system used in this study is presented in Fig. 1, including an aqueous phase (bottom layer) of molten salt hydrate (concentrated LiBr solution) with a small quantity of acid as a co-catalyst and an organic phase (top layer) of

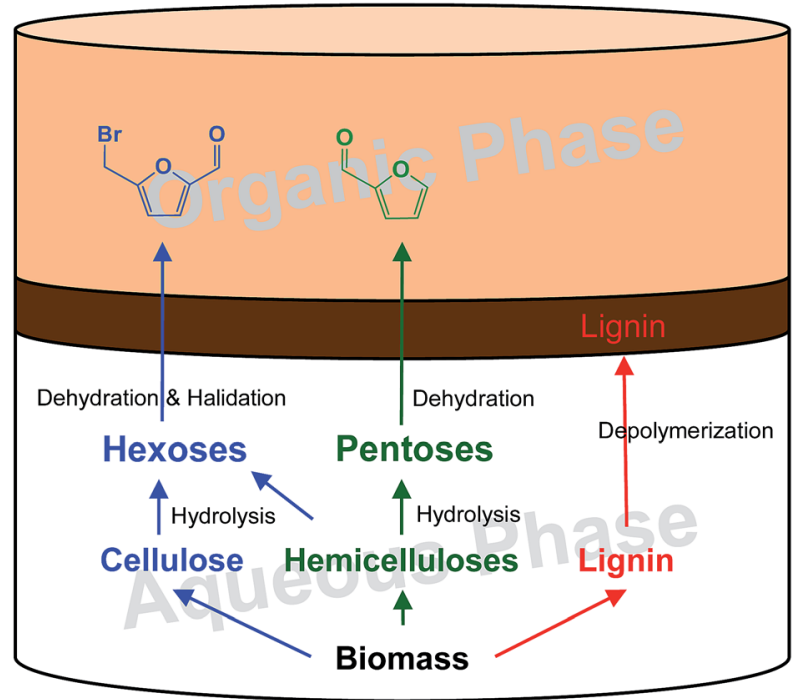

Fig. 1 Biphasic system consisting of an aqueous phase of lithium bromide solution and an organic phase of solvent for converting lignocellulose to FF and BMF and depolymerized lignin. extraction solvent. In the aqueous phase, cellulose and hemicelluloses are first dissolved, then hydrolysed into hexoses and pentoses, and further dehydrated or derived to BMF and FF, respectively. Meanwhile, lignin is depolymerized and left over as a solid residue. As FF and BMF have better solubility (partition) in the organic phase than in the aqueous phase, they are immediately extracted into the organic phase when formed, which prevents them from further decomposition and condensation. Lignin is cumulated between the two phases because its density is lower than that of the molten salt hydrate but higher than that of the organic solvent. The solid lignin can be easily separated from the system by filtration, while the solvent can be recycled for the following batch after FF and BMF are recovered. The aqueous phase can be reused after necessary regeneration such as adjustment of the salt and acid concentrations.

A molten salt hydrate is basically a concentrated aqueous solution of an inorganic salt. The concentration of the molten salt hydrate varies from salt to salt, dependent on the coordination number of the salt cation. ${ }^{39}$ Molten salt hydrates have similar properties with ionic liquids, such as low vapor pressure, high boiling point, and ability to swell and dissolve cellulose, but the former is less expensive, more environmentfriendly, easier to recycle, and less viscous than the latter. For example, LiBr has very high solubility in water (166.7 and 266.0 $\mathrm{g} / 100 \mathrm{~mL}$ at 20 and $100{ }^{\circ} \mathrm{C}$, respectively). $\mathrm{LiBr} \cdot 3 \mathrm{H}_{2} \mathrm{O}$ (equivalent to $61.7 \%, \mathrm{w} / \mathrm{w}$ ) is a liquid at room temperature with very low viscosity ( $\sim 3 \mathrm{mPa} S$ ). These unique properties make the molten $\mathrm{LiBr}$ hydrate an attractive reaction medium for the conversion of lignocellulosic biomass.

In a perfect molten salt hydrate, all water molecules are tightly bound to the inner coordination sphere of the cation, leaving the anion naked in the system. ${ }^{40}$ For example, in the molten salt hydrate of lithium bromide $\left(\mathrm{LiBr} \cdot 3 \mathrm{H}_{2} \mathrm{O}\right)$ used in this study, lithium cation $\left(\mathrm{Li}^{+}\right)$has octahedral coordination geometry and needs 6 oxygen atoms to coordinate. Since the oxygen of each water molecule is able to coordinate with two lithium ions, the molar ratio of $\mathrm{LiBr}$ to $\mathrm{H}_{2} \mathrm{O}$ is $1: 3$ in the molten salt hydrate of LiBr. While $\mathrm{Li}^{+}$is surrounded by water molecules, $\mathrm{Br}^{-}$ is naked and free in the solution. The free bromide anion $\left(\mathrm{Br}^{-}\right)$ tends to associate with the $\mathrm{H}$ of cellulose hydroxyl groups and form hydrogen bonds. On the other hand, $\mathrm{Li}^{+}$is very oxophilic and able to interact with the $\mathrm{O}$ of cellulose hydroxyl groups when dissociated from the coordinated water molecules by heating and, in particular, when part of the water in the system is consumed for hydrolysis of cellulose and hemicelluloses. The cellulose- $\mathrm{Br}^{-}$and cellulose- $\mathrm{Li}^{+}$associations or interactions disrupt the inter- and intra-molecular hydrogen bonding of cellulose, thereby breaking the tight crystalline matrix of cellulose, thus leading to the swelling and dissolution of cellulose. The dissolution generates a homogeneous reaction medium and facilitates the hydrolysis of cellulose and hemicelluloses. In addition, the enhanced acidity in molten salt hydrate, ${ }^{\mathbf{4 1}}$ compared with that in water at the same acid concentration, promotes the hydrolysis of the polysaccharides to monomeric saccharides and the following dehydration of the monomeric saccharides to furans. Furthermore, the free 
bromide anions in the solution are strong nucleophiles, which are able to catalyze the dehydration of saccharides to furans and likely the cleavage of $\beta$-O- 4 ether bonds of lignin resulting in the depolymerization of lignin, ${ }^{22,27,30,31}$ which will be further discussed later. Finally, the salting-out effect of the inorganic salt ( $\mathrm{LiBr}$ ) can enhance the partition coefficient of BMF and FF in the extraction solvent and thereby facilitate effective extraction of the furans from the aqueous phase to the organic phase. ${ }^{\mathbf{1 7 4 2}}$

It is known that a biphasic system consisting of aqueous and organic phases was able to prevent or reduce undesired decomposition and condensation of furan products accumulated in the aqueous phase. In the previous studies, different biphasic systems such as $\mathrm{HCl}-\mathrm{H}_{3} \mathrm{PO}_{4} / \mathrm{CHCl}_{3}$, ethyl acetate/ILs, acid/alkylphenol, $\mathrm{HCl} /$ chlorinated hydrocarbons, and $\mathrm{AlCl}_{3}$ $\cdot 6 \mathrm{H}_{2} \mathrm{O}-\mathrm{NaCl} / \mathrm{THF}$ were investigated for the production of furanbased products. ${ }^{\mathbf{1 8 3 2 - 3 4 , 4 3 - 4 6}}$ Considering the unique properties of the molten salt hydrate, the biphasic system consisting of extraction solvent and molten salt hydrate was expected to enhance the yield of the furan products from lignocellulosic biomass.

\subsection{Transformation of cellulose to BMF in the biphasic system}

First, the transformation of pure cellulose to halide-methyl furfural (BMF or CMF) in the proposed biphasic system was investigated. Different molten salt hydrates, including $\mathrm{LiBr}$, $\mathrm{LiCl}$, and $\mathrm{CaBr}_{2}$, were tested and compared. Reaction temperature, time, and $\mathrm{HBr}$ (co-catalyst) loading were optimized through preliminary tests designed by RSM (Tables S1-S3 and Fig. S6 $\dagger$ ). From the RSM optimization, suggested optimal reaction conditions were $125{ }^{\circ} \mathrm{C}, 0.181 \mathrm{~mL} \mathrm{HBr}$ loading (equivalent to $0.16 \mathrm{M}$ of $\mathrm{HBr}$ in aqueous phase), and $126 \mathrm{~min}$. As summarized in Table $1, \mathrm{LiBr}$ with $\mathrm{HBr}$ as a co-catalyst gave the highest yield (90.3\%). Under the same reaction conditions $\left(125{ }^{\circ} \mathrm{C}\right.$ and $\left.126 \mathrm{~min}\right)$ and molar salt concentration $\left(\mathrm{LiBr} \cdot 3 \mathrm{H}_{2} \mathrm{O}\right.$ and $\left.\mathrm{LiCl} \cdot 3 \mathrm{H}_{2} \mathrm{O}\right)$, the product yield of the $\mathrm{LiBr}$ system $(90.3 \%$ $\mathrm{BMF})$ was much higher than that of the LiCl system $(72.9 \%$ CMF). This observation suggests that LiBr was more efficient than $\mathrm{LiCl}$ at the conversion of cellulose into furans (BMF or $\mathrm{CMF}$ ), which could be attributed to the differences in size,

Table 1 Conversion of cellulose into halide-methyl furfural by different halide salts, organic solvents, and mineral acids ${ }^{a}$

\begin{tabular}{llll}
$\begin{array}{l}\text { Halide } \\
\text { salt }\end{array}$ & Organic solvent & Acids & BMF/CMF yield [\%] \\
\hline $\mathrm{LiBr}$ & DCM & $\mathrm{HBr}$ & $90.3 \pm 2.0$ \\
$\mathrm{CaBr}_{2}$ & $\mathrm{DCM}$ & $\mathrm{HBr}$ & $70.3 \pm 3.9$ \\
$\mathrm{LiCl}$ & $\mathrm{DCM}$ & $\mathrm{HBr}$ & $72.9 \pm 2.8$ \\
$\mathrm{LiBr}$ & Toluene & $\mathrm{HBr}$ & $64.8 \pm 4.6$ \\
$\mathrm{LiBr}$ & Cyclohexane & $\mathrm{HBr}$ & $26.7 \pm 5.2$ \\
$\mathrm{LiBr}$ & Benzene & $\mathrm{HBr}$ & $76.5 \pm 0.7$ \\
$\mathrm{LiBr}$ & DCM & $\mathrm{HCl}$ & $77.3 \pm 0.8$
\end{tabular}

${ }^{a}$ Note: reaction conditions: $2 \%(\mathrm{w} / \mathrm{v})(200 \mathrm{mg})$ of biomass substrates loading with $0.16 \mathrm{M}$ of $\mathrm{HBr}$ in $10 \mathrm{~mL}$ of aqueous phase, $20 \mathrm{~mL}$ of different organic solvents in organic phase, $125{ }^{\circ} \mathrm{C}, 500 \mathrm{rpm}$ for stirring, 126 min. charge density, and electronegativity of $\mathrm{Br}^{-}$and $\mathrm{Cl}^{-} \cdot \mathrm{Br}^{-}$has larger radius and higher nucleophilicity, which make it more efficient in swelling and dissolving cellulose than $\mathrm{Cl}^{-}$. Calcium bromide $\left(\mathrm{CaBr}_{2} \cdot 6 \mathrm{H}_{2} \mathrm{O}\right)$ gave a lower $\mathrm{BMF}$ yield than lithium bromide $\left(\mathrm{LiBr} \cdot 3 \mathrm{H}_{2} \mathrm{O}\right)$, implying that the cation of a molten salt hydrate was also an important factor affecting the conversion of cellulose to BMF. The performance difference between $\mathrm{Ca}^{2+}$ and $\mathrm{Li}^{+}$was likely related to their size, coordination geometry and structure, and concentration and solubility in water, which affect their interactions with $\mathrm{Br}^{-}$, water, and cellulose. Lu et al. recently reported that the structure and size of the cation affected the dissolution of cellulose. ${ }^{47}$ At the same molar concentration $(0.16 \mathrm{M})$ of proton $(1.29 \mathrm{w} / \mathrm{v} \% \mathrm{HBr}$ and $0.58 \mathrm{w} / \mathrm{v} \%$ $\mathrm{HCl}$, respectively) in the aqueous phase, $\mathrm{HCl}$ gave lower product yield than $\mathrm{HBr}(77.3 \%$ vs. $90.3 \%$ in Table 1$)$.

Efficient recovery of the furans is as important as conversion itself; therefore, selection of extraction solvent for the organic phase in this biphasic system is crucial. A good solvent should be immiscible with the aqueous phase, stable under the reaction conditions, and easy to separate from the products for reuse. In addition, $\mathrm{FF}$ and $\mathrm{BMF}$, but not the salt and acid catalyst, should have high partition coefficient in the solvent. The results shown in Table 1 indicate that DCM gave the highest BMF yield, but it needs to be replaced with greener solvent. Toluene was reported to be an effective extraction solvent of FF and HMF in previous studies, ${ }^{15,34}$ but its performance in the present biphasic system was poorer than DCM, giving a BMF yield of only $64.8 \%$. Cyclohexane turned out to be not a good solvent because only $26.7 \%$ BMF was recovered under the same conditions. Benzene showed the potential as an extraction solvent (76.5\% BMF yield), although its performance needs to be improved by further investigation.

It was observed that the volume ratio of organic phase to aqueous phase was also a critical factor that affected not only the load of the solvent but also the total yield of BMF. As shown in Fig. 2, under the same reaction conditions, when the volume ratio of organic phase to aqueous phase increased from 1.0 to 2.0 , the recovery yield of BMF increased from $73.9 \%$ to $90.3 \%$.

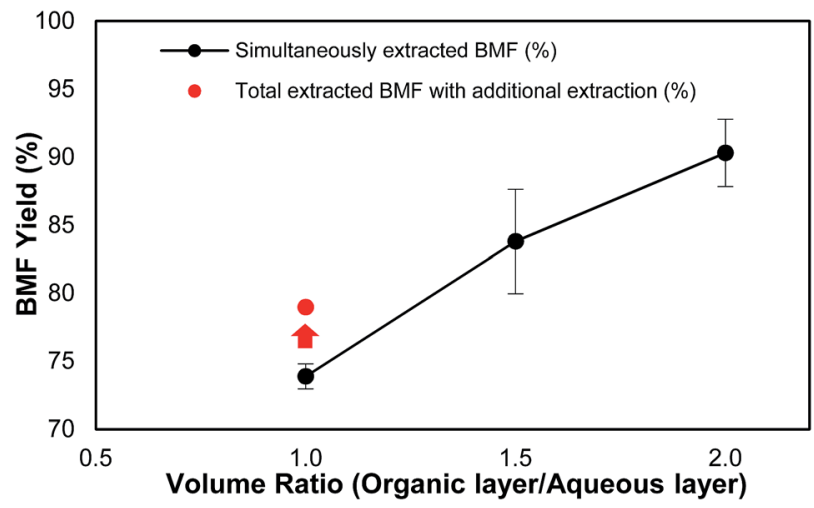

Fig. 2 Effect of volume ratio of organic phase to aqueous phase on BMF recovery. Note: reaction conditions: 2\% (w/v) $(200 \mathrm{mg})$ of cellulose loading with $0.16 \mathrm{M}$ of $\mathrm{HBr}$ in $10 \mathrm{~mL}$ of $\mathrm{LiBr}$ hydrate $(61.6 \%)$, $10-20 \mathrm{~mL}$ of organic phase (DCM), $125{ }^{\circ} \mathrm{C}, 500 \mathrm{rpm}$ for stirring, $126 \mathrm{~min}$. 
The results suggest that sufficient organic solvent be important for satisfactory BMF recovery. To investigate how much the generated BMF was extracted to the solvent layer at the ratio of 1.0, the aqueous phase was further extracted after the reaction with fresh DCM, and the combined ratio of solvent to aqueous phase was 2. Additional 5.1\% BMF was recovered (Fig. 2), and the total HMF yield ended up to $79.0 \%$, which, however, was still $11.3 \%$ lower than that $(90.3 \%)$ from the experiment with the ratio of 2 . The results indicate that sufficient solvent is crucial to extract the newly formed BMF and prevent it from condensation or further degradation. Continuous extraction of the product during the reaction might be able to further reduce solvent use and improve BMF yield, which needs further investigation.

The effect of LiBr concentration on BMF production from cellulose was investigated to demonstrate the importance of molten salt hydrate. As shown in Fig. 3, the investigated $\mathrm{LiBr}$ concentrations include $20.2,40.8,44.6,49.1,54.7,61.6$, and $70.7 \%(\mathrm{w} / \mathrm{w})$, which correspond to the molar ratios of $\mathrm{H}_{2} \mathrm{O}$ to LiBr of 19, 7, 6, 5, 4, 3, and 2, respectively. The results clearly indicated the cruciality of $\mathrm{LiBr}$ concentration. No BMF was detected at a concentration of $20.2 \% \mathrm{LiBr}\left(\mathrm{LiBr} \cdot 19 \mathrm{H}_{2} \mathrm{O}\right)$, and no significant $\mathrm{BMF}$ was formed until the $\mathrm{LiBr}$ concentration reached $49.1 \%\left(\mathrm{LiBr} \cdot 5 \mathrm{H}_{2} \mathrm{O}\right)$. The highest BMF yield $(90.3 \%)$ was observed at $61.6 \%$ concentration $\left(\mathrm{LiBr} \cdot 3 \mathrm{H}_{2} \mathrm{O}\right)$, at which the molten salt hydrate of $\mathrm{LiBr}$ is formed. Further increasing $\mathrm{LiBr}$ concentration to $70.7 \%\left(\mathrm{LiBr} \cdot 2 \mathrm{H}_{2} \mathrm{O}\right)$ did not enhance but reduced BMF yield (Fig. 3), which was likely because the water deficient condition at high $\mathrm{LiBr}$ concentration depressed the cellulose hydrolysis. The results verified the hypothesis that the molten salt hydrate system is crucial for the conversion of cellulose to BMF.

\subsection{Proposed reaction mechanism of cellulose to BMF}

To understand the pathway from cellulose to BMF, the conversion of glucose, fructose, cellobiose, and cellulose to BMF was investigated. Cellobiose, glucose, and fructose were selected

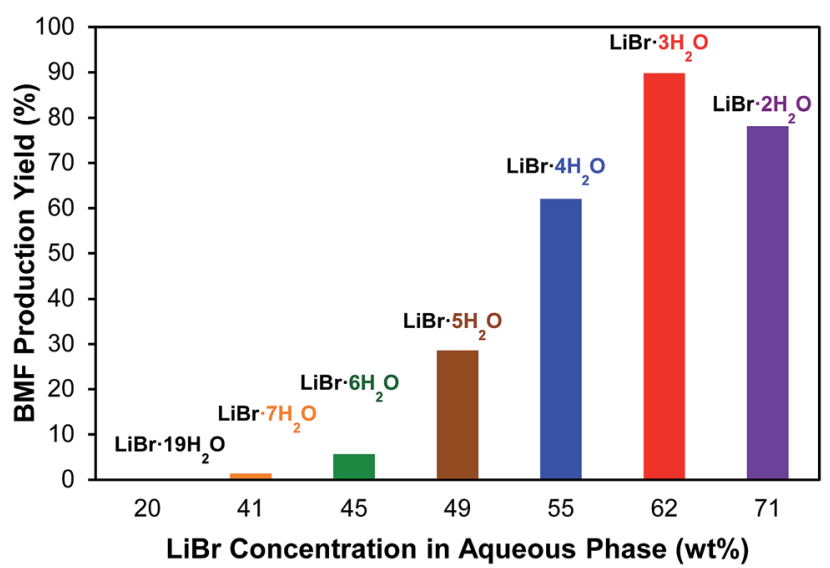

Fig. 3 Production of BMF from cellulose at different $\mathrm{LiBr}$ concentrations. Note: reaction conditions: $2 \%(\mathrm{w} / \mathrm{v})(200 \mathrm{mg})$ of cellulose loading with $0.16 \mathrm{M}$ of $\mathrm{HBr}$ in $10 \mathrm{~mL}$ of different concentration of $\mathrm{LiBr}$ hydrates, $20 \mathrm{~mL}$ of organic phase (DCM), $125^{\circ} \mathrm{C}, 500 \mathrm{rpm}$ for stirring, $126 \mathrm{~min}$.

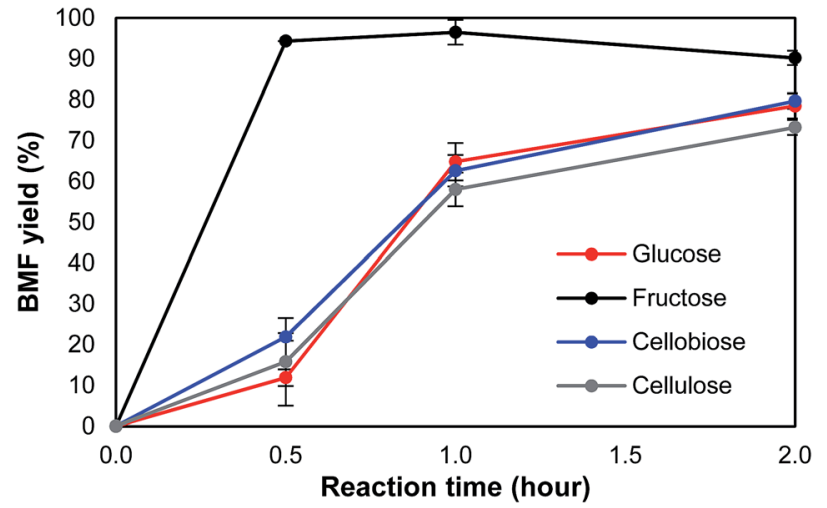

Fig. 4 Conversion of different carbohydrates into BMF. Note: reaction conditions: $2 \%(\mathrm{w} / \mathrm{v})(200 \mathrm{mg})$ of carbohydrates loading with $0.16 \mathrm{M}$ of $\mathrm{HBr}$ in $10 \mathrm{~mL}$ of $\mathrm{LiBr}$ hydrate (61.6\%), $20 \mathrm{~mL}$ of organic phase (DCM), $125^{\circ} \mathrm{C}, 500 \mathrm{rpm}$ for stirring, 0-120 min.

because they are possible intermediates of the conversion from cellulose to BMF. As shown in Fig. 4, 94.3\% of fructose was converted to BMF within the first $30 \mathrm{~min}$; the BMF yield decreased slightly when the reaction was extended to $2 \mathrm{~h}$, probably, in part, due to the condensation/decomposition of BMF. Since glucose and cellobiose are the hydrolysis products of cellulose, they were expected to have faster reactions and higher BMF yield than cellulose; however, under the same conditions, the conversion of glucose, cellobiose, and cellulose to $\mathrm{BMF}$ followed a similar trend with regarding to reaction rate and product yield. The conversion of glucose, cellobiose, and cellulose was slower and resulted in lower BMF yield than that of fructose. As fructose was quickly converted to BMF with high yield (Fig. 4), it is reasonable to hypothesize that the hydrolysis of cellulose to glucose was probably not the rate-limiting reaction, but rather the isomerization of glucose to fructose likely controlled the overall reaction rate.

Based on the results and discussions above, the pathway from cellulose to BMF in molten salt hydrate $\left(\mathrm{LiBr} \cdot 3 \mathrm{H}_{2} \mathrm{O}\right)$ is proposed in Fig. 5, which includes the steps of cellulose dissolution, cellulose hydrolysis to glucose, glucose

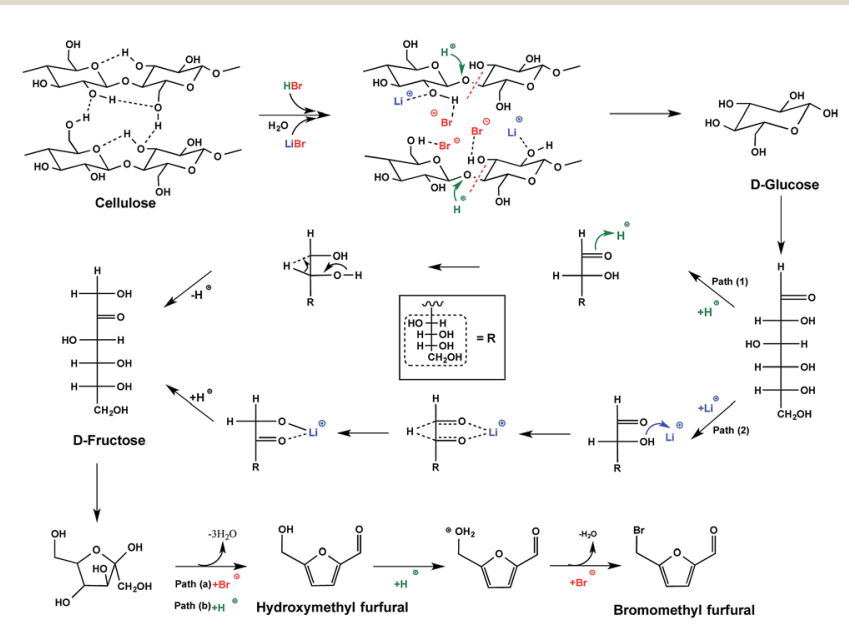

Fig. 5 Proposed conversion pathways from cellulose to BMF. 
isomerization to fructose, fructose dehydration to $\mathrm{HMF}$, and HMF bromination to BMF. First of all, cellulose is swelled and dissolved in the molten salt hydrate because of the disruption of intermolecular and intramolecular hydrogen bonds of cellulose by the formation of $\mathrm{Br}-\mathrm{H} \cdots \mathrm{O}$ and $\mathrm{Li}-\mathrm{O} \cdots \mathrm{H}$ interactions, as discussed above. The dissolved cellulose is more readily and quickly hydrolyzed into glucose by acid than solid and crystalline cellulose. As mentioned above (Fig. 4), dissolution and hydrolysis of cellulose seem to not be the rate-limiting steps of cellulose conversion to BMF. The following step is the isomerization of glucose to fructose. Because of the presence of $\mathrm{H}^{+}$and $\mathrm{Li}^{+}$in the system, there are two possible isomerization pathways catalyzed by them, respectively. In path 1 , glucose is isomerized to fructose through the acid-catalyzed intramolecular hydrogen transfer from C-2 to C-1, initiated by protonation of the carbonyl oxygen atom on $\mathrm{C}-1 .^{48,49}$ In path 2 , the isomerization is achieved by a metal-catalyzed hydrogen transfer between C-2 and C-1 via a hydride shift. ${ }^{50-52} \mathrm{Li}^{+}$attacks the $\mathrm{O}$ of the hydroxyl group on $\mathrm{C}$ 2 and leads to the formation of intermediate, a 5-member complex involving $\mathrm{Li}^{+}$, which then rearranges to fructose. In the third step, fructose is dehydrated to HMF, catalyzed by either $\mathrm{Br}^{-53}$ or $\mathrm{H}^{+} 54$ in the acidic molten salt hydrate system. The last step of cellulose-to-BMF is the bromination of HMF. The hydroxyl group of HMF is protonated to form a good leaving group (water), which is then displaced by bromide through a $\mathrm{S}_{\mathrm{N}} 2$ mechanism.

\subsection{Transformation of real biomass in the biphasic system}

The biphasic system was applied to different types of real biomass including switchgrass (energy crop), corn stover (agricultural residue), poplar and aspen (hardwood), and Douglas fir (softwood). As summarized in Table 2, the process was able to convert cellulose and hemicelluloses in the biomass simultaneously to BMF and FF, respectively, with high yields. The molar yields of BMF and FF were calculated based on original hexoses and pentoses in the biomass (Table $\mathrm{S} 4 \dagger)$, respectively. Under the same conditions, aspen had the highest BMF yield (87.1\%), while corn stover, switchgrass, and poplar gave similar yields of approximately 70\%. Softwood Douglas fir had the lowest BMF yield, which was presumably attributed to its different physical structure and chemical composition, in particular high lignin content. The yield of FF

Table 2 Conversion of different biomass into BMF and FF using molten $\mathrm{LiBr}$ hydrate in a biphasic system ${ }^{a}$

\begin{tabular}{lll}
\hline Biomass & BMF yield [\%] & Furfural yield [\%] \\
\hline Corn stover & $71.3 \pm 1.6$ & $69.4 \pm 5.6$ \\
Switchgrass & $70.2 \pm 0.7$ & $51.2 \pm 2.0$ \\
Poplar & $72.2 \pm 2.8$ & $61.9 \pm 1.3$ \\
Aspen & $87.1 \pm 1.5$ & $83.9 \pm 5.9$ \\
Douglas fir & $63.9 \pm 2.3$ & $57.3 \pm 0.0$
\end{tabular}

${ }^{a}$ Note: reaction conditions: $2 \%(\mathrm{w} / \mathrm{v})(200 \mathrm{mg})$ of different biomass loading with $0.16 \mathrm{M}$ of $\mathrm{HBr}$ in $10 \mathrm{~mL}$ of $\mathrm{LiBr}$ hydrate $(61.6 \%), 20 \mathrm{~mL}$ of organic phase (DCM), $125{ }^{\circ} \mathrm{C}, 500 \mathrm{rpm}$ for stirring, $126 \mathrm{~min}$.

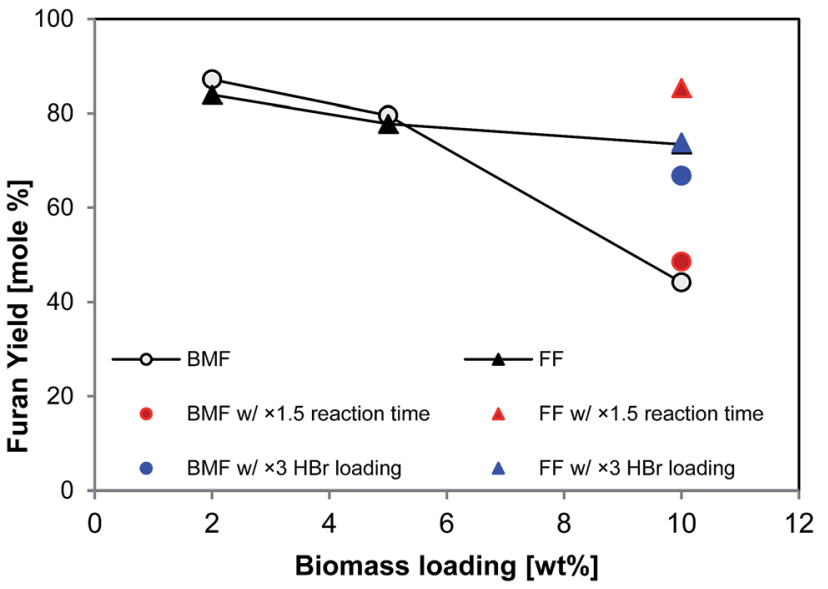

Fig. 6 BMF and FF production from Aspen with different substrates loading. Note: reaction conditions: $2-10 \%(\mathrm{w} / \mathrm{v})$ of aspen loading with $0.16 \mathrm{M}$ of $\mathrm{HBr}$ in $10 \mathrm{~mL}$ of $\mathrm{LiBr}$ hydrate $(61.6 \%), 20 \mathrm{~mL}$ of organic phase (DCM), $125^{\circ} \mathrm{C}, 500 \mathrm{rpm}$ for stirring, $126 \mathrm{~min}$.

varied from biomass to biomass within the range of $51-84 \%$, dependent on the species.

\subsection{Transformation of biomass at high solid loading}

It is apparent that increasing solid loading could improve the efficiency and productivity of biomass conversion processes. As all the tests above (Table 2) were conducted at low solid loading ( $2 \mathrm{wt} \%$ in aqueous phase), higher solid loading was explored. As shown in Fig. 6, the yields of BMF and FF from aspen were $87 \%$ and $84 \%$, respectively, at $2 \mathrm{wt} \%$ solid loading, and slightly decreased to $80 \%$ and $78 \%$, respectively, at $5 \%$ aspen loading; however, the yields significantly dropped when solid loading was further increased to $10 \%$. In particular, the BMF yield sharply dropped to $44 \%$, which was probably due to the insufficient swelling and hydrolysis of cellulose at high solid loading. Extending reaction time from 126 to $189 \mathrm{~min}$ brought FF yield back to $85 \%$ (solid red triangle in Fig. 6), but BMF yield was only slightly improved (solid red circle in Fig. 6), implying that extending reaction time did not substantially promote the conversion of cellulose. Differently, increasing catalyst $(\mathrm{HBr}$ ) loading by 3 times (to $0.48 \mathrm{M}$ in aqueous phase) elevated the BMF yield to $67 \%$ (solid blue circle in Fig. 6), but FF yield was not improved, which was probably due to the enhanced FF condensation by the additional acid. These results suggest that additional acid catalyst and longer reaction time are necessary to reach satisfactory FF and BMF yields at high solid loading.

\subsection{Characterization of separated lignin}

When cellulose and hemicelluloses of the biomass were converted to BMF and FF, respectively, lignin was left over as an insoluble residue between the two phases, as shown in Fig. 1 and $\mathrm{S} 2 . \dagger$ The separated lignin was preliminarily investigated to elucidate the change of lignin and evaluate the potential for lignin co-products. Firstly, purity of three lignin samples from switchgrass, poplar, and Douglas fir was analyzed. It was found 
Table 3 Molecular weight of the depolymerized lignin in the biphasic system from poplar, switchgrass, and Douglas fir ${ }^{a, b}$

\begin{tabular}{llll}
\hline Lignin & PDI & $M_{\mathrm{n}}\left(\mathrm{g} \mathrm{mol}^{-1}\right)$ & $M_{\mathrm{w}}\left(\mathrm{g} \mathrm{mol}^{-1}\right)$ \\
\hline Poplar lignin & 2.60 & 500 & 1300 \\
Switchgrass lignin & 2.50 & 400 & 1000 \\
Douglas fir lignin & 2.60 & 500 & 1300
\end{tabular}

${ }^{a}$ Note: reaction conditions: $2 \%(\mathrm{w} / \mathrm{v})$ of poplar/switchgrass/Douglas fir loading with $0.16 \mathrm{M}$ of $\mathrm{HBr}$ in $10 \mathrm{~mL}$ of LiBr hydrate $(61.6 \%), 20 \mathrm{~mL}$ of organic phase (DCM), $125{ }^{\circ} \mathrm{C}, 500 \mathrm{rpm}$ for stirring, $126 \mathrm{~min} .{ }^{b}$ PDI - polydispersity index $\left(=M_{\mathrm{w}} / M_{\mathrm{n}}\right)$. that $97 \%$ of the solid residues were lignin, and trace or no residual carbohydrates were detected (Table $\mathrm{S} 5 \dagger$ ). This observation indicates that the present biphasic system not only completely convert cellulose and hemicelluloses into BMF and FF, respectively, but produce high-purity lignin.

The molecular weight of the lignin samples was estimated by GPC after acetylation. It was found that the acetylated lignins were not completely soluble in THF, which was used as the eluent for the GPC analysis. The weight average molecular weights of the THF-soluble fractions of the lignins are summarized in Table 3. They fell between 1000 and $1300 \mathrm{~g} \mathrm{~mol}^{-1}$, which was much lower
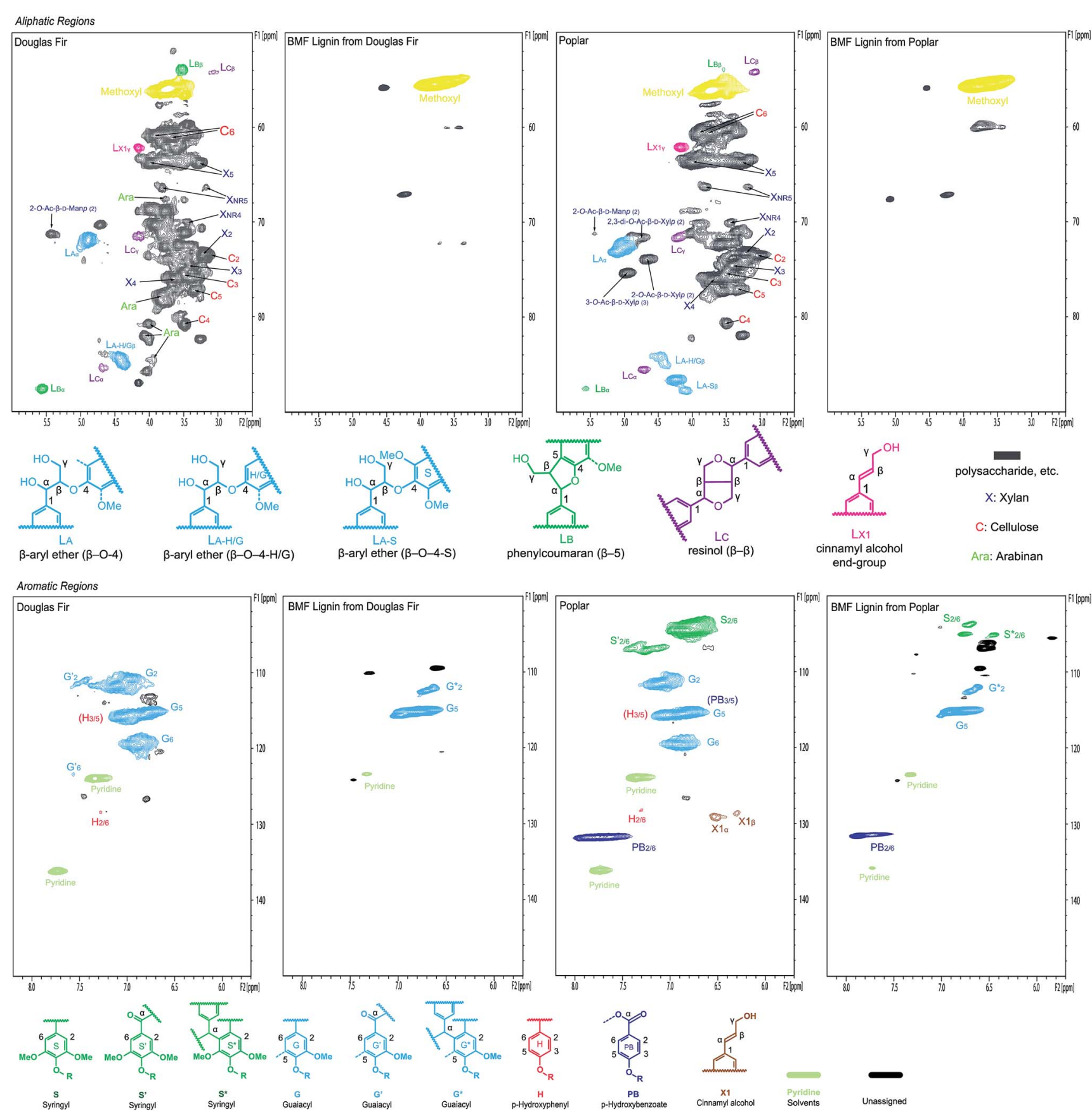

Fig. 7 2D NMR spectra of biomass (Douglas fir and poplar) whole cell wall and separated lignins in DMSO- $d_{6} /$ pyridine- $d_{5}(4: 1)$. 
than those of native lignins (milled wood lignins) (5900-23 $500 \mathrm{~g}$ $\mathrm{mol}^{-1}$ ) and separated lignins from other processes (2000-8700 $\mathrm{g}$ $\left.\mathrm{mol}^{-1}\right){ }_{.5}$ The results suggest that the THF-soluble lignin was extensively depolymerized during the reaction. The THF-insoluble lignin represented the fraction that was either insufficiently depolymerized or repolymerized (condensed) during the reaction.

The separated lignins from softwood Douglas fir and hardwood poplar were further characterized using NMR and compared with the native lignins in the original woods to understand the changes in the chemical structure of lignins during the transformation of cellulose and hemicelluloses. In the aliphatic (lignin side-chain and polysaccharides) regions (top row in Fig. 7) of the NMR spectra, almost all of the peaks for polysaccharides in both Douglas fir and poplar were removed after the reaction, verifying that the separated lignins were carbohydrate-free, which is consistent with the lignin purity analysis. In addition, major inter-linkage ( $\beta$-aryl ether) in lignin was clearly removed, which is the direct evidence of lignin depolymerization. Aromatic regions (bottom row in Fig. 7) also indicate that the separated lignins were significantly different from the native lignins in Douglas fir and poplar, respectively. In particular, the $\mathrm{G}_{2}$ and $\mathrm{G}_{6}$ correlation peaks in both softwood and hardwood lignins were decreased and shifted after the reaction in the separated lignins. Similarly, the $S_{2 / 6}$ correlation peak in hardwood lignin diminished significantly after the reaction. This might result either from the deconstruction of aromatic rings or from the condensations of lignin at these sites on benzene rings $\left(\mathrm{C}_{2}\right.$ and $\left.\mathrm{C}_{6}\right)$ with the $\alpha$-C of other structural units under acidic condition. ${ }^{56-58}$

\section{Conclusion}

In summary, the biphasic process including acidic molten salt hydrate $\left(\mathrm{LiBr} \cdot 3 \mathrm{H}_{2} \mathrm{O}\right)$ investigated in this study could effectively convert cellulose and hemicelluloses of lignocellulosic biomass into BMF and FF, respectively, with high yields at moderate temperature. With unique properties, the molten salt hydrate of lithium bromide was able to swell and dissolve cellulose, enhance the hydrolysis of cellulose to glucose, catalyze the isomerization of glucose to fructose and the dehydration of fructose to HMF, and brominate HMF to BMF. Simultaneously, lignin of the biomass was extensively depolymerized and separated for co-products.

\section{Acknowledgements}

This research was supported by National Science Foundation (CBET-1159561 and CBET 1236562), USDA McIntire Stennis project (WIS01861), and Wisconsin Alumni Research Foundation (WARF) Accelerator Program. The authors thank Dr Hoon Kim for his kind assistance with whole cell wall gel NMR and discussion of NMR spectra.

\section{Notes and references}

1 N. Sathitsuksanoh, A. George and Y. H. P. Zhang, J. Chem. Technol. Biotechnol., 2013, 88, 169-180.
2 J. Serrano-Ruiz and J. Dumesic, in Catalysis for Alternative Energy Generation, ed. L. Guczi and A. Erdôhelyi, Springer, New York, 2012, ch. 2, pp. 29-56.

3 V. B. Agbor, N. Cicek, R. Sparling, A. Berlin and D. B. Levin, Biotechnol. Adv., 2011, 29, 675-685.

4 J. N. Chheda, G. W. Huber and J. A. Dumesic, Angew. Chem., Int. Ed., 2007, 46, 7164-7183.

5 M. J. Climent, A. Corma and S. Iborra, Green Chem., 2014, 16, 516-547.

6 B. Joshi, M. R. Bhatt, D. Sharma, J. Jarina, R. Malla and L. Sreerama, Biotechnol. Mol. Biol. Rev., 2011, 6, 172-182.

7 C. Liu, H. Wang, A. M. Karim, J. Sun and Y. Wang, Chem. Soc. Rev., 2014, 43, 7594-7623.

8 J. Hill, E. Nelson, D. Tilman, S. Polasky and D. Tiffany, Proc. Natl. Acad. Sci. U. S. A., 2006, 103, 11206-11210.

9 J. Akhtar, A. Idris and R. Abd Aziz, Appl. Microbiol. Biotechnol., 2014, 98, 987-1000.

10 C. Gao, C. Ma and P. Xu, Biotechnol. Adv., 2011, 29, 930-939. 11 R. D. Cortright, M. Sanchez-Castillo and J. A. Dumesic, Appl. Catal., B, 2002, 39, 353-359.

12 G. Marcotullio and W. d. Jong, Carbohydr. Res., 2011, 346, 1291-1293.

13 J. M. Cruz, J. M. Domínguez, H. Domínguez and J. C. Parajó, Biotechnol. Lett., 2000, 22, 1895-1898.

14 J. J. Bozell and G. R. Petersen, Green Chem., 2010, 12, 539-554. 15 M. Mascal and E. B. Nikitin, Green Chem., 2010, 12, 370-373. 16 S. Van de Vyver, J. Thomas, J. Geboers, S. Keyzer, M. Smet, W. Dehaen, P. A. Jacobs and B. F. Sels, Energy Environ. Sci., 2011, 4, 3601-3610.

17 B. Saha and M. M. Abu-Omar, Green Chem., 2014, 16, 24-38. 18 Y. Román-Leshkov, C. J. Barrett, Z. Y. Liu and J. A. Dumesic, Nature, 2007, 447, 982-985.

19 L. Hu, G. Zhao, W. Hao, X. Tang, Y. Sun, L. Lin and S. Liu, RSC Adv., 2012, 2, 11184-11206.

20 K. Yan, G. Wu, T. Lafleur and C. Jarvis, Renewable Sustainable Energy Rev., 2014, 38, 663-676.

21 X. Tong, Y. Ma and Y. Li, Appl. Catal., A, 2010, 385, 1-13.

22 A. Gandini and M. Belgacem, J. Polym. Environ., 2002, 10, 105-114.

23 P. Gallezot, Chem. Soc. Rev., 2012, 41, 1538-1558.

24 C. Li, Z. K. Zhao, A. Wang, M. Zheng and T. Zhang, Carbohydr. Res., 2010, 345, 1846-1850.

25 R.-J. van Putten, J. C. van der Waal, E. de Jong, C. B. Rasrendra, H. J. Heeres and J. G. de Vries, Chem. Rev., 2013, 113, 1499-1597.

26 M. E. Zakrzewska, E. Bogel-łukasik and R. Bogel-łukasik, Chem. Rev., 2011, 111, 397-417.

27 S. Dutta, S. De, B. Saha and M. I. Alam, Catal. Sci. Technol., 2012, 2, 2025-2036.

28 L. Wang, F. Yuan, X. Niu, C. Kang, P. Li, Z. Li and Y. Zhu, RSC $A d v .$, 2016, 6, 40175-40184.

29 Y. Xing, B. Yan, Z. Yuan and K. Sun, RSC Adv. , 2016, 6, 5908159090.

30 J. B. Binder, J. J. Blank, A. V. Cefali and R. T. Raines, ChemSusChem, 2010, 3, 1268-1272.

31 N. Kumari, J. K. Olesen, C. M. Pedersen and M. Bols, Eur. J. Org. Chem., 2011, 1266-1270. 
32 W. Gao, Y. Li, Z. Xiang, K. Chen, R. Yang and D. S. Argyropoulos, Molecules, 2013, 18, 7675-7685.

33 M. Mascal and E. B. Nikitin, ChemSusChem, 2009, 2, 859861.

34 M. Mascal and E. B. Nikitin, Angew. Chem., Int. Ed., 2008, 120, 8042-8044.

35 M. Mascal and S. Dutta, in Selective Catalysis for Renewable Feedstocks and Chemicals, Springer, 2014, pp. 41-83.

36 F. S. Asghari and H. Yoshida, Ind. Eng. Chem. Res., 2006, 45, 2163-2173.

37 F. S. Asghari and H. Yoshida, Ind. Eng. Chem. Res., 2007, 7703-7710.

38 X. Qi, M. Watanabe, T. M. Aida and J. R. L. Smith, Green Chem., 2009, 11, 1273-1484.

39 H. Leipner, S. Fischer, E. Brendler and W. Voigt, Macromol. Chem. Phys., 2000, 201, 2041-2049.

40 S. Sen, J. D. Martin and D. S. Argyropoulos, ACS Sustainable Chem. Eng., 2013, 1, 858-870.

41 J. A. Duffy and M. D. Ingram, Inorg. Chem., 1978, 17, 27982802.

42 T. Tan and S. Aravinth, Fluid Phase Equilib., 1999, 163, 243257.

43 M. Brasholz, K. von Känel, C. H. Hornung, S. Saubern and J. Tsanaktsidis, Green Chem., 2011, 13, 1114-1117.

44 E. I. Gürbüz, S. G. Wettstein and J. A. Dumesic, ChemSusChem, 2012, 5, 383-387.
45 Y. Yang, C.-W. Hu and M. M. Abu-Omar, Green Chem., 2012, 14, 509-513.

46 B. R. Caes and R. T. Raines, ChemSusChem, 2011, 4, 353-356. 47 B. Lu, A. Xu and J. Wang, Green Chem., 2014, 16, 1326-1335.

48 D. W. Harris and M. S. Feather, Carbohydr. Res., 1973, 30, 359-365.

49 N. Shi, Q. Liu, L. Ma, T. Wang, Q. Zhang, Q. Zhang and Y. Liao, RSC Adv., 2014, 4, 4978-4984.

50 C. A. Collyer, K. Henrick and D. M. Blow, J. Mol. Biol., 1990, 212, 211-235.

51 R. W. Nagorski and J. P. Richard, J. Am. Chem. Soc., 2001, 123, 794-802.

52 M. Moliner, Y. Román-Leshkov and M. E. Davis, Proc. Natl. Acad. Sci. U. S. A., 2010, 107, 6164-6168.

53 Y.-N. Li, J.-Q. Wang, L.-N. He, Z.-Z. Yang, A.-H. Liu, B. Yu and C.-R. Luan, Green Chem., 2012, 14, 2752-2758.

54 S. Caratzoulas and D. G. Vlachos, Carbohydr. Res., 2011, 346, 664-672.

55 A. Tolbert, H. Akinosho, R. Khunsupat, A. K. Naskar and A. J. Ragauskas, Biofuels, Bioprod. Biorefin., 2014, 8, 836-856.

56 K. Shimada, S. Hosaya and T. Ikeda, J. Wood Chem. Technol., 1997, 17, 57-72.

57 J. Li, G. Henriksson and G. Gellerstedt, Bioresour. Technol., 2007, 98, 3061-3068.

58 X. Yang, N. Li, X. Lin, X. Pan and Y. Zhou, J. Agric. Food Chem., 2016, 64, 8379-8387. 